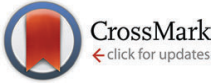

Cite this: Phys. Chem. Chem. Phys., 2015, 17, 8467

Received 12th December 2014, Accepted 27th January 2015

DOI: $10.1039 / \mathrm{c} 4 \mathrm{cp} 05836 \mathrm{~d}$

www.rsc.org/pccp

\section{Structural properties of methanol-water binary mixtures within the quantum cluster equilibrium model $\dagger$}

\author{
G. Matisz, ${ }^{a b}$ A.-M. Kelterer, ${ }^{* c}$ W. M. F. Fabian ${ }^{d}$ and S. Kunsági-Máté ${ }^{a b}$
}

Density functional theory (B3LYP-D3, M06-2X) has been used to calculate the structures, interaction energies and vibrational frequencies of a set of 93 methanol-water clusters of different type (cubic, ring, spiro, lasso, bicyclic), size and composition. These interaction energies have been used within the framework of the Quantum Cluster Equilibrium Theory (QCE) to calculate cluster populations as well as thermodynamic properties of binary methanol-water mixtures spanning the whole range from pure water to pure methanol. The necessary parameters $a_{\mathrm{mf}}$ and $b_{\mathrm{xv}}$ of the QCE model were obtained by fitting to experimental isobars of $\mathrm{MeOH}-\mathrm{H}_{2} \mathrm{O}$ mixtures with different $\mathrm{MeOH}$ content. The cubic and spiro motifs dominate the distribution of methanol-water clusters in the mixtures with a maximum of mixed clusters at $x(\mathrm{MeOH})=0.365$. Reasonable agreement with experimental data as well as earlier molecular dynamics simulations was found for excess enthalpies $H^{\mathrm{E}}$, entropies $S^{\mathrm{E}}$ as well as Gibbs free energies of mixing $G^{\mathrm{E}}$. In contrast, heat capacities $C_{p}$ and $C_{p}^{E}$ showed only poor agreement with experimental data.

\section{Introduction}

Preferential or selective solvation ${ }^{1-4}$ of a solute in binary solvent mixtures, where the composition of the solvation shell differs from the composition of the bulk solvent phase, can have significant effects on the physicochemical properties of the solution. The observable differences are obviously in connection with the molecular associations present in the binary solvent mixtures. Several studies can be found in the literature addressing the investigation of binary liquids regarding structural aspects. For instance, in a recent study, Wakisaka published a summary of experimental results ${ }^{5-8}$ related to the cluster structures possible in binary liquid mixtures of water- $\mathrm{MeOH}$, water-EtOH, water$n$-PrOH and water- $n$ - $\mathrm{BuOH}$ using fragmentation of liquid droplets

\footnotetext{
${ }^{a}$ Department of General and Physical Chemistry, University of Pécs, Ifjúság 6, 7624 Pécs, Hungary

${ }^{b}$ János Szentágothai Research Center, Ifjúság 20, 7624 Pécs, Hungary

${ }^{c}$ Institute of Physical and Theoretical Chemistry, Graz University of Technology, NAWI Graz, Stremayrgasse 9/I, 8010 Graz, Austria.E-mail: kelterer@tugraz.at

${ }^{d}$ Institute of Chemistry, University of Graz, NAWI Graz, Heinrichstr. 28, $8010 \mathrm{Graz}$, Austria

$\dagger$ Electronic supplementary information (ESI) available: Fitting parameters $a_{\mathrm{mf}}$, $b_{\mathrm{xv}}$ see Tables S1 (with $c 8$ clusters) and S2 (without $c 8$ clusters). Table S3 $\Delta G^{298}$ / $\mathrm{H}$-bond and populations at different molar fraction. Fig. S1 Number of clusters for specific $x(\mathrm{MeOH})$; Fig. S2 Benchmark of methods against MP2 for ring clusters; M06-2X data are shown in Fig. S3 ( $\left.E_{\text {int }}\right)$, S4 (cluster populations), S5 (cluster distributions), S6 $\left(H^{\mathrm{E}}, S^{\mathrm{E}}, G^{\mathrm{E}}\right), \mathrm{S} 8\left(C_{\mathrm{p}}, C_{\mathrm{p}}^{\mathrm{E}}\right)$, and Fig. S7 ( $C_{\mathrm{P}}^{\mathrm{E}}$ for B3LYP-D3). Cartesian coordinates of all 93 clusters for B3LYP-D3 and M06-2X method as zip file. See DOI: $10.1039 / \mathrm{c} 4 \mathrm{cp} 05836 \mathrm{~d}$
}

and mass spectrometric detection of the ionized clusters. ${ }^{9,10}$ Solvent relaxation time measurements in mixtures of $n$ - $\mathrm{BuOH}$ with $\mathrm{MeOH}$, EtOH, and $\mathrm{PrOH}$ indicated a substantial change of the solvation shell at a specific molar fraction of $n$-BuOH. ${ }^{11}$ Similarly, measurement of the solvent relaxation time by phase fluorimetry of phenols in binary $\mathrm{EtOH}$-water mixtures resulted in a change from mono- to bi-exponential when the EtOH content exceeded a critical value. ${ }^{12}$ In view of the importance of such solvent mixtures a detailed understanding of this selective/preferential solvation at an atomic level is essential. Besides experimental investigations quantum chemical calculations also have been used to determine the properties of such clusters formed by different solvent molecules, including e.g. methanol-water clusters up to four-membered rings ${ }^{13}$ or methanolbenzene clusters. ${ }^{14}$ Of particular importance for the present investigation are those dealing with water ${ }^{15-17}$ and/or methanol ${ }^{18-21}$ clusters addressing mainly the structural properties, binding energies and electronic properties of these clusters. Specifically, rather comprehensive calculations of $(\mathrm{MeOH})_{n}$ clusters with $n$ up to $n=15$ using a variety of computational procedures have been carried out by Thakkar and coworkers. ${ }^{21}$ In addition to methanol clusters those of higher primary alcohols (up to $n$-hexanol) were treated by Golub et al. ${ }^{19}$

A powerful tool for the description and theoretical modelling of structure and properties of liquids is the quantum cluster equilibrium (QCE) theory ${ }^{22}$ which is based on quantum chemically calculated cluster/molecular properties and the application of statistical thermodynamics. So far this procedure almost 
exclusively has been applied to neat liquids, like water, ${ }^{23-34}$ methanol, ${ }^{28,35-38}$ ethanol, $^{28,38-41}$ propan-1-ol, ${ }^{38}$ butan-1-ol, ${ }^{38}$ benzyl alcohol, ${ }^{39}$ 2,2-dimethyl-3-ethyl-3-pentanol, ${ }^{39,42}$ formic acid, ${ }^{43,44}$ liquid ammonia, ${ }^{27,45,46}$ phosphine, ${ }^{27}$ hydrogen sulfide, ${ }^{27}$ $N$-methylacetamide, ${ }^{47-49}$ liquid sulfur, ${ }^{50}$ and liquid hydrogenfluoride. ${ }^{34,51-53}$ Recently, in addition to the static thermodynamic description by the QCE model, the kinetics of the hydrogen bond formation and proton transfer in water clusters has been studied by Weinhold. ${ }^{54}$ To the best of our knowledge, the only binary system for which the QCE model has been applied until now is the waterdimethyl-sulfoxide (DMSO) ${ }^{55}$ binary mixture. Evidently the reason is not limited interest in binary (or ternary) systems, but rather arise from technical difficulties for a proper description of such mixtures. These include both the approximations inherent in the QCE model, as well as the more complex structure of liquids consisting of more than one component. While in the binary system treated so far by the QCE model one component acts as a hydrogen bond acceptor (DMSO) and the other (water) as donor, in binary mixtures of alcohols or alcohol-water, as used in our previous experimental investigations, ${ }^{11,12}$ both components can act as hydrogen bond acceptors as well as hydrogen bond donors.

As a first step to a detailed understanding of such binary solvent mixtures in this study we want to present a quantum cluster equilibrium study of the $\mathrm{MeOH}$-water system with different composition ranging from pure water to pure $\mathrm{MeOH}$. We have chosen this system not only as it represents the prototype of binary mixture used in our previous investigations but also since several theoretical modeling studies, mainly by molecular dynamics, ${ }^{56-64}$ as well as experimental investigations, ${ }^{65-68}$ have been published.

Moreover, since apparently the QCE model has for the first time been applied to a binary liquid mixture where both components can act as hydrogen bond acceptors and also as hydrogen bond donors, the $\mathrm{MeOH}-$ water system presents an important test case for the quantum cluster equilibrium model of such mixtures.

\section{Computational methods}

The methanol-water cluster structures have been optimized using the B3LYP density functional ${ }^{69-72}$ augmented with the D3 dispersion correction ${ }^{73}$ of Grimme et al. as implemented in the ORCA 2.9.1 program. ${ }^{74}$ The TZVP basis set ${ }^{75}$ has been used both for the optimizations and for the vibrational analysis. The intracluster interaction energies $\left(E_{\text {int }}\right)$ were determined using the QZVP basis set ${ }^{76}$ according to eqn (1) and are corrected for the basis set superposition error (BSSE) ${ }^{77}$

$$
E_{\text {int }}=E_{\text {cluster }}-\sum E_{\text {monomers }}=E_{\text {cluster }}-i \cdot E_{\mathrm{MeOH}}-j \cdot E_{\mathrm{H}_{2} \mathrm{O}}
$$

where $i, j$ are the numbers of monomers of methanol and water, respectively, participating in forming the cluster, while $E$ is the electronic energy.

Gibbs free energies of interaction $\Delta G_{\text {int }}$ were obtained from the BSSE-corrected B3LYP-D3/QZVP interaction energies combined with non-thermal (ZPE) and thermal corrections $\mathrm{d} G$ corr resulting from the TZVP frequency analysis at $T=298.15 \mathrm{~K}$ and $p=1 \mathrm{~atm}$. For the rotational partition function the appropriate symmetry numbers ( $\sigma=2$ for $w 1, m 2 w 2 r, w 4 r, m 4 r, m 2 w 6 ; \sigma=3$ for $m 6 r ; \sigma=4$ for $w 8 c$ and $m 4 w 4 c$; for all other clusters $\sigma=1$ ) were used.

$$
\Delta G_{\text {int }}=E_{\text {int }}(\mathrm{BSSE}-\mathrm{QZVP})+\left[\mathrm{d} G_{\text {cluster }}^{\text {corr }}-\sum \mathrm{d} G_{\text {monomers }}^{\text {corr }}\right](\mathrm{TZVP})
$$

All calculations were done with a very tight SCF cutoff and integration grid size of 5 , together with tight geometry optimization criteria. In addition to B3LYP-D3 the M06-2X density functional $^{78-80}$ as implemented in Gaussian 09 program $^{81}$ in combination with the aug-cc-pVTZ basis set ${ }^{82}$ was also used. The motivation for choosing these two functional was mainly based on the works of Thakkar ${ }^{21}$ and Golub ${ }^{19}$ as well as our previous experience. ${ }^{14}$

The QCE calculations have been performed using the developer version of the PEACEMAKER 2.0 program (rev. 572) of the research group of Kirchner. ${ }^{33}$ The extension of the program for binary systems is described in detail in ref. 55. Besides the electronic energy, interaction energy, principal moments of inertia and harmonic vibrational frequencies of clusters, to obtain the statistical thermodynamics data via partition functions, two fitting parameters $a_{\mathrm{mf}}$ and $b_{\mathrm{xv}}$ are used in the QCE theory. The recently developed one-parameter QCE variant so far has only been applied to neat liquids. ${ }^{34}$

Based on the parameter $a_{\mathrm{mf}}$, the interaction energies of each cluster with the surrounding particles/clusters can be defined as an additive term $\left(u_{\text {int }}\right)$ to the intracluster interaction energies $\left(E_{\text {int }}\right)$. The parameter $b_{\mathrm{xv}}$ gives the correction for the calculation of the excluded volume $V_{\text {excl }}$.

The mean field potential $u_{\text {int }}$ in the case of the binary mixture is given by eqn (3), for each cluster individually:

$$
u^{\mathrm{int}}=-a_{\mathrm{mf}} \frac{i+j}{V_{\mathrm{m}}}
$$

The excluded volume for the total system is defined as

$$
V_{\mathrm{excl}}=b_{\mathrm{xv}} \cdot V_{\mathrm{vdw}}
$$

where $i, j$ denote the number of molecules of methanol and water, respectively, which are participating in forming a given cluster, and $V_{\mathrm{vdw}}$ denotes total volumes of the clusters. The sum of all cluster volumes $V_{\mathrm{vdw}}$ compose $1 \mathrm{~mol}$ of monomers.

In the PEACEMAKER program the aforementioned two parameters are sampled with the aims to make agreement between the experimental and the calculated isobars while searching for the phase with the lowest Gibbs energy at the given pressure and temperature. Since only the liquid phase was considered, the mean absolute deviation function was selected in the program for comparison of the calculated and experimental isobars during the sampling process. The experimental isobars were obtained from the Landolt-Börnstein database. ${ }^{68}$ Both $a_{\mathrm{mf}}$ and $b_{\mathrm{xv}}$ were kept constant over the whole temperature range since there is no provision for a temperature dependence of these two parameters in the PEACEMAKER program. 
Table 1 The clusters included in the cluster set describing the methanol-water binary liquid mixture ${ }^{a}$

\begin{tabular}{|c|c|c|c|c|c|c|c|c|}
\hline \multirow[b]{2}{*}{ Cluster class } & \multirow[b]{2}{*}{ Cluster structure } & \multirow[b]{2}{*}{ Number of H-bonds } & \multicolumn{3}{|c|}{ B3LYP-D3/QZVP } & \multicolumn{3}{|c|}{ M06-2X/aug-cc-pVTZ } \\
\hline & & & $E_{\text {int }}$ & $\Delta G_{\mathrm{int}}^{298}$ & $\Delta G_{\text {int }}^{298} /$ monomer & $E_{\text {int }}$ & $\Delta G_{\mathrm{int}}^{298}$ & $\Delta G_{\text {int }}^{299} /$ monomer \\
\hline \multirow{2}{*}{ mon } & $m 1$ & 0 & 0.00 & 0.00 & 0.00 & 0.00 & 0.00 & 0.00 \\
\hline & $w 1$ & 0 & 0.00 & 0.00 & 0.00 & 0.00 & 0.00 & 0.00 \\
\hline \multirow[t]{4}{*}{$\operatorname{dim}$} & $m 2$ & 1 & -24.69 & 16.89 & 8.44 & -24.44 & 14.98 & 7.49 \\
\hline & $m 1 w 1$ & 1 & -21.77 & 12.06 & 6.03 & -20.90 & 13.90 & 6.95 \\
\hline & $w 1 m 1$ & 1 & -24.39 & 11.67 & 5.84 & -23.83 & 12.92 & 6.46 \\
\hline & $w 2$ & 1 & -21.87 & 11.06 & 5.53 & -21.31 & 13.65 & 6.83 \\
\hline \multirow[t]{4}{*}{ r3 } & $m 3 r$ & 3 & -75.08 & 19.72 & 6.57 & -72.00 & 15.42 & 5.14 \\
\hline & $m 2 w 1 r$ & 3 & -73.16 & 16.48 & 5.49 & -71.60 & 17.07 & 5.69 \\
\hline & $m 1 w 2 r$ & 3 & -71.16 & 17.29 & 5.76 & -70.96 & 15.62 & 5.21 \\
\hline & $w 3 r$ & 3 & -69.07 & 17.96 & 5.99 & -70.39 & 17.83 & 5.94 \\
\hline \multirow[t]{5}{*}{ r4 } & $m 4 r$ & 4 & -133.08 & 17.94 & 4.48 & -121.90 & 1.25 & 0.31 \\
\hline & $m 3 w 1 r$ & 4 & -130.20 & 13.33 & 3.33 & -121.27 & 6.68 & 1.67 \\
\hline & $m 2 w 2 r$ & 4 & -127.46 & 16.78 & 4.19 & -120.71 & 9.98 & 2.49 \\
\hline & $m 1 w 3 r$ & 4 & -124.89 & 11.29 & 2.82 & -119.68 & 13.07 & 3.27 \\
\hline & $w 4 r$ & 4 & -122.36 & 14.70 & 3.68 & -118.77 & 17.15 & 4.29 \\
\hline \multirow[t]{6}{*}{ r5 } & $m 5 r$ & 5 & -176.80 & 21.49 & 4.30 & -163.32 & 14.30 & 2.86 \\
\hline & $m 4 w 1 r$ & 5 & -173.36 & 19.23 & 3.85 & -159.68 & 8.05 & 1.61 \\
\hline & $m 3 w 2 r$ & 5 & -169.81 & 21.25 & 4.25 & -157.59 & 11.13 & 2.23 \\
\hline & $m 2 w 3 r$ & 5 & -165.96 & 22.54 & 4.51 & -155.94 & 18.27 & 3.65 \\
\hline & $m 1 w 4 r$ & 5 & -163.26 & 22.90 & 4.58 & -155.59 & 18.62 & 3.72 \\
\hline & $w 5 r$ & 5 & -160.58 & 20.76 & 4.15 & -154.13 & 22.93 & 4.59 \\
\hline \multirow[t]{7}{*}{ r6 } & $m 6 r$ & 6 & -217.84 & 35.91 & 5.98 & -200.47 & 0.60 & 0.10 \\
\hline & $m 5 w 1 r$ & 6 & -214.21 & 35.51 & 5.92 & -198.91 & 6.39 & 1.07 \\
\hline & $m 4 w 2 r$ & 6 & -210.60 & 33.30 & 5.55 & -197.35 & 15.34 & 2.56 \\
\hline & $m 3 w 3 r$ & 6 & -207.21 & 30.58 & 5.10 & -195.72 & 18.73 & 3.12 \\
\hline & $m 2 w 4 r$ & 6 & -203.84 & 32.73 & 5.45 & -194.11 & 24.65 & 4.11 \\
\hline & $m 1 w 5 r$ & 6 & -200.76 & 29.77 & 4.96 & -192.28 & 27.35 & 4.56 \\
\hline & $w 6 r$ & 6 & -197.78 & 30.39 & 5.07 & -190.47 & 31.31 & 5.22 \\
\hline \multirow[t]{8}{*}{ r7 } & $m 7 r$ & 7 & -261.88 & 42.60 & 6.09 & -242.00 & 29.90 & 4.27 \\
\hline & $m 6 w 1 r$ & 7 & -257.54 & 40.59 & 5.80 & -240.49 & 34.72 & 4.96 \\
\hline & $m 5 w 2 r$ & 7 & -253.78 & 43.01 & 6.14 & -238.75 & 40.97 & 5.85 \\
\hline & $m 4 w 3 r$ & 7 & -250.44 & 40.53 & 5.79 & -237.95 & 44.14 & 6.31 \\
\hline & $m 3 w 4 r$ & 7 & -245.83 & 42.51 & 6.07 & -234.13 & 48.37 & 6.91 \\
\hline & $m 2 w 5 r$ & 7 & -239.41 & 45.81 & 6.54 & -230.56 & 39.58 & 5.65 \\
\hline & $m 1 w 6 r$ & 7 & -234.20 & 37.28 & 5.33 & -226.72 & 43.78 & 6.25 \\
\hline & $w 7 r$ & 7 & -227.96 & 49.45 & 7.06 & -220.17 & 37.24 & 5.32 \\
\hline \multirow[t]{7}{*}{ bc7(5-4) } & $m 6 w 1 b c$ & 8 & -263.59 & 42.38 & 6.05 & -242.49 & 34.45 & 4.92 \\
\hline & $m 5 w 2 b c$ & 8 & -260.87 & 37.81 & 5.40 & -243.50 & 36.35 & 5.19 \\
\hline & $m 4 w 3 b c$ & 8 & -255.85 & 37.44 & 5.35 & -241.75 & 41.28 & 5.90 \\
\hline & $m 3 w 4 b c$ & 8 & -250.83 & 41.43 & 5.92 & -240.26 & 37.97 & 5.42 \\
\hline & $m 2 w 5 b c$ & 9 & -255.42 & 39.40 & 5.63 & -246.11 & 31.00 & 4.43 \\
\hline & $m 1 w 6 b c$ & 9 & -251.33 & 36.66 & 5.24 & -244.61 & 36.80 & 5.26 \\
\hline & $w 7 b c$ & 9 & -247.39 & 34.26 & 4.89 & -241.68 & 38.40 & 5.49 \\
\hline \multirow[t]{5}{*}{ s5(3-3) } & $m 4 w 1 s$ & 6 & -145.57 & 52.10 & 10.42 & -140.81 & 32.08 & 6.42 \\
\hline & $m 3 w 2 s$ & 6 & -143.10 & 51.88 & 10.38 & -140.26 & 34.73 & 6.95 \\
\hline & $m 2 w 3 s$ & 6 & -140.95 & 47.91 & 9.58 & -139.93 & 34.67 & 6.93 \\
\hline & $m 1 w 4 s$ & 6 & -138.81 & 42.77 & 8.55 & -139.29 & 35.73 & 7.15 \\
\hline & $w 5 s$ & 6 & -136.99 & 42.51 & 8.50 & -138.93 & 37.01 & 7.40 \\
\hline s6(3-4) & $m 5 w 1 s$ & 7 & -203.39 & 48.52 & 8.09 & -190.70 & 29.28 & 4.88 \\
\hline & $m 4 w 2 s$ & 7 & -201.22 & 48.74 & 8.12 & -190.35 & 32.49 & 5.41 \\
\hline & $m 3 w 3 s$ & 7 & -198.04 & 41.48 & 6.91 & -189.37 & 32.71 & 5.45 \\
\hline & $m 2 w 4 s$ & 7 & -195.69 & 41.17 & 6.86 & -188.49 & 30.42 & 5.07 \\
\hline & $m 1 w 5 s$ & 7 & -192.80 & 42.76 & 7.13 & -187.71 & 33.78 & 5.63 \\
\hline & $w 6 s$ & 7 & -190.27 & 43.51 & 7.25 & -186.73 & 38.60 & 6.43 \\
\hline s9(5-5) & $m 8 w 1 s$ & 10 & -357.17 & 55.40 & 6.16 & -327.91 & 46.11 & 5.12 \\
\hline & $m 7 w 2 s$ & 10 & -352.89 & 57.28 & 6.36 & -325.19 & 49.64 & 5.52 \\
\hline & $m 6 w 3 s$ & 10 & -348.04 & 59.15 & 6.57 & -328.16 & 39.34 & 4.37 \\
\hline & $m 5 w 4 s$ & 10 & -342.96 & 61.85 & 6.87 & -324.78 & 42.49 & 4.72 \\
\hline & $m 4 w 5 s$ & 10 & -339.60 & 60.48 & 6.72 & -319.22 & 37.37 & 4.15 \\
\hline
\end{tabular}


Table 1 (continued)

\begin{tabular}{|c|c|c|c|c|c|c|c|c|}
\hline \multirow[b]{2}{*}{ Cluster class } & \multirow[b]{2}{*}{ Cluster structure } & \multirow[b]{2}{*}{ Number of H-bonds } & \multicolumn{3}{|c|}{ B3LYP-D3/QZVP } & \multicolumn{3}{|c|}{ M06-2X/aug-cc-pVTZ } \\
\hline & & & $E_{\text {int }}$ & $\Delta G_{\mathrm{int}}^{298}$ & $\Delta G_{\mathrm{int}}^{298} /$ monomer & $E_{\text {int }}$ & $\Delta G_{\mathrm{int}}^{298}$ & $\Delta G_{\text {int }}^{298} /$ monomer \\
\hline & $m 3 w 6 s$ & 10 & -334.50 & 60.68 & 6.74 & -316.61 & 40.36 & 4.48 \\
\hline & $m 2 w 7 s$ & 10 & -331.41 & 57.48 & 6.39 & -315.10 & 43.19 & 4.80 \\
\hline & $m 1 w 8 s$ & 10 & -328.49 & 53.80 & 5.98 & -313.82 & 49.65 & 5.52 \\
\hline & $w 9 s$ & 10 & -325.62 & 54.85 & 6.09 & -312.61 & 50.78 & 5.64 \\
\hline \multirow[t]{11}{*}{ s11(6-6) } & $m 10 w 1 s$ & 12 & -445.33 & 72.99 & 6.64 & -412.86 & 64.48 & 5.86 \\
\hline & $m 9 w 2 s$ & 12 & -429.57 & 90.54 & 8.23 & -406.99 & 72.29 & 6.57 \\
\hline & $m 8 w 3 s$ & 12 & -424.96 & 93.75 & 8.52 & -395.11 & 52.32 & 4.76 \\
\hline & $m 7 w 4 s$ & 12 & -421.45 & 90.79 & 8.25 & -395.51 & 50.19 & 4.56 \\
\hline & $m 6 w 5 s$ & 12 & -417.84 & 87.80 & 7.98 & -393.85 & 48.42 & 4.40 \\
\hline & $m 5 w 6 s$ & 12 & -413.08 & 88.83 & 8.08 & -389.70 & 46.33 & 4.21 \\
\hline & $m 4 w 7 s$ & 12 & -409.66 & 90.71 & 8.25 & -388.05 & 54.69 & 4.97 \\
\hline & $m 3 w 8 s$ & 12 & -406.37 & 86.19 & 7.84 & -386.33 & 56.45 & 5.13 \\
\hline & $m 2 w 9 s$ & 12 & -407.83 & 76.25 & 6.93 & -391.44 & 57.29 & 5.21 \\
\hline & $m 1 w 10 s$ & 12 & -404.44 & 73.24 & 6.66 & -389.72 & 62.27 & 5.66 \\
\hline & $w 11 s$ & 12 & -401.20 & 74.77 & 6.80 & -388.26 & 66.66 & 6.06 \\
\hline $15(4-1)$ & $m 3 w 1 r-m 1$ & 5 & -160.57 & 33.92 & 6.78 & -150.76 & 35.86 & 7.17 \\
\hline $16(5-1)$ & $m 5 r-w 1$ & 6 & -209.40 & 41.25 & 6.87 & -193.96 & 33.10 & 5.52 \\
\hline \multirow[t]{2}{*}{$16(4-2)$} & $m 3 w 1 r-2 m 1(1,1)$ & 6 & -195.04 & 56.63 & 9.44 & -184.46 & 50.15 & 8.36 \\
\hline & $m 3 w 1 r-2 m 1(1,3)$ & 6 & -189.89 & 60.69 & 10.11 & -177.78 & 44.24 & 7.37 \\
\hline \multirow[t]{10}{*}{ b6(4-4) } & $m 2 m w m 2$ & 7 & -220.47 & 27.84 & 4.64 & -204.74 & 21.47 & 3.58 \\
\hline & mwmwm2 & 7 & -215.86 & 33.51 & 5.58 & -201.60 & 18.49 & 3.08 \\
\hline & mwmwmw & 7 & -212.42 & 30.65 & 5.11 & -200.34 & 22.54 & 3.76 \\
\hline & $w 2 m w m w$ & 7 & -210.13 & 26.32 & 4.39 & -199.51 & 23.86 & 3.98 \\
\hline & $m w w 2 m w$ & 7 & -208.13 & 33.47 & 5.58 & -198.48 & 26.23 & 4.37 \\
\hline & $w 2 m w w 2$ & 7 & -207.15 & 27.90 & 4.65 & -198.26 & 26.78 & 4.46 \\
\hline & $w 2 w 2 w 2$ & 7 & -202.96 & 31.01 & 5.17 & -196.48 & 31.91 & 5.32 \\
\hline & $m w w 2 w 2$ & 7 & -205.30 & 30.21 & 5.03 & -197.28 & 28.74 & 4.79 \\
\hline & $m 2 w 2 m w$ & 7 & -211.51 & 36.48 & 6.07 & -202.07 & 27.86 & 4.64 \\
\hline & $m 2 w 2 m 2$ & 7 & -216.05 & 31.16 & 5.19 & -203.55 & 25.13 & 4.19 \\
\hline \multirow[t]{6}{*}{ c8 } & $m 5 w 3 c$ & 11 & -331.17 & 24.08 & 3.01 & -307.14 & 30.56 & 3.82 \\
\hline & $m 4 w 4 c$ & 12 & -341.18 & 17.11 & 2.14 & -319.27 & 21.34 & 2.67 \\
\hline & $m 3 w 5 c$ & 12 & -337.67 & 15.94 & 1.99 & -318.44 & 23.83 & 2.98 \\
\hline & $m 2 w 6 c$ & 12 & -333.81 & 20.12 & 2.51 & -317.63 & 26.52 & 3.32 \\
\hline & $m 1 w 7 c$ & 12 & -330.03 & 20.77 & 2.60 & -316.91 & 28.57 & 3.57 \\
\hline & $w 8 c$ & 12 & -326.18 & 27.15 & 3.39 & -315.84 & 30.39 & 3.80 \\
\hline c8-lasso & $m 4 w 4 c-m 1$ & 13 & -369.71 & 38.44 & 4.27 & -350.33 & 42.17 & 4.69 \\
\hline
\end{tabular}

In these QCE calculations it is especially important to provide a representative and comprehensive set of cluster motifs as it has been shown earlier. ${ }^{31}$ In this study 93 clusters like ring, spiro, book, bicyclic, lasso and cubic structures have been included. The full cluster set (95 including the two monomers) with the naming convention is provided in Table 1 and some representative structures illustrating the notation are presented in Fig. 1. The various structures of the clusters required by the QCE model are denoted as $m_{x} w_{y} t$ where $m$ and $w$ indicate the monomers $\mathrm{MeOH}(m)$ and water $(w) ; x$ and $y$ mean the numbers of the corresponding monomers, and $t$ indicates the cluster type i.e. mon: monomer, dim: dimer, r: monocyclic ring, bc: bicyclic ring, s: spiro cluster ${ }^{31}$ in which two rings are connected through a common water molecule which establishes four hydrogen-bonds (2 donor and 2 acceptor) towards the two rings; l: lasso, b: book, c: cubic. The ring size of monocyclic clusters (r-type clusters) equals $x+y$; for spiro cluster besides the total clusters size in parentheses also the numbers of molecules participating in the connected rings are given. For lasso structures in parentheses the numbers of molecules within the ring and of those connected to the ring as well as the points of attachment are given. In the case of seven-membered clusters besides monocyclic rings also bi- and polycyclic structures consisting of a five- and four-membered ring, denoted by $b c 7(5-4)$, have been found. Because previously linear chain and lasso structures were found to be less important ${ }^{35,37,38}$ in the cases of primary alcohols, especially $\mathrm{MeOH}$, within the QCE model only a few of these type of clusters were included. The reason of their smaller contribution originates from the smaller increase (as absolute value) in the interaction energy with the cluster size compared with cyclic structures where the cooperativity effect ${ }^{18,83,84}$ plays a key role. 

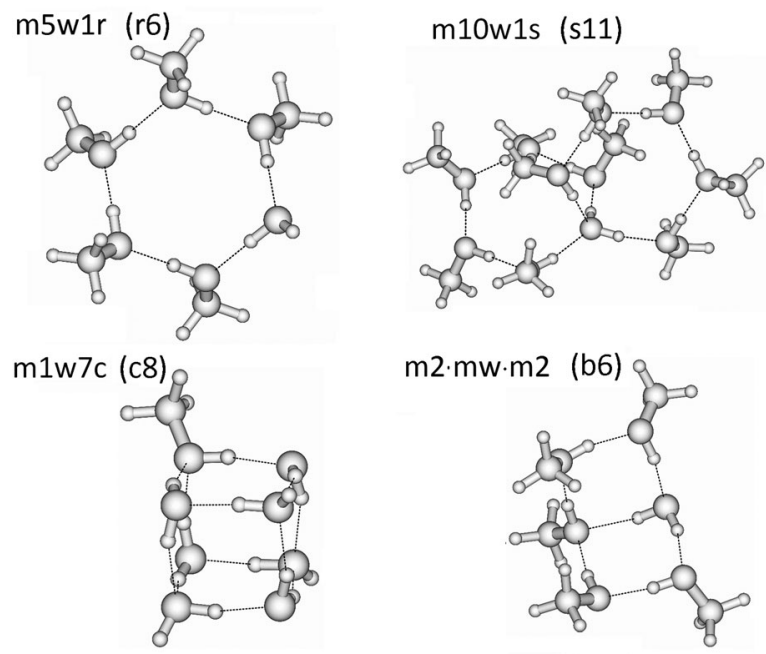

m3w1r-m1 (I5)
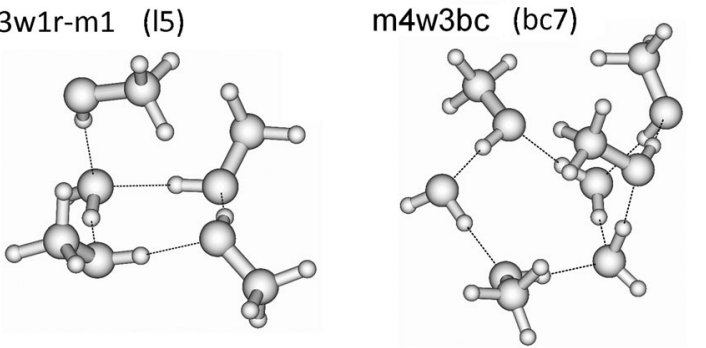

Fig. 1 Plot of the main cluster types (ring, spiro, cubic, book, lasso, and bicyclic).

Because not only the temperature but also the composition dependence of the cluster distribution were planned to be studied, the ring, spiro and cubic clusters were created with all the possible compositions. Hence, starting from pure water clusters, water molecules were successively replaced by methanol molecules with the restriction that the cluster motifs remain unchanged. Therefore, in the case of the spiro clusters one water molecule had to be retained; in the case of the cubic $c 8$ clusters four water molecules are needed to be kept; in case of the ring type clusters, no such restriction applies. The replacements have been carried out according to the previous findings: ${ }^{37}$ in structures with adjacent $\mathrm{MeOH}$ molecules the methyl groups were oriented to different directions (i.e. up-down, respectively). Furthermore, the replacements have been done more or less randomly within the structures, keeping in mind that the appropriate selection of cluster motifs $^{31}$ (i.e. inclusion of the cubic, the ring and the spiro cluster classes) is more important than the strict placement of the methyl groups or using strictly the putative global minimum structure of a given cluster type. Cartesian coordinates of all clusters optimized with B3LYP-D3/TZVP and M06-2X/aug-cc-pVTZ methods are available as ESI. $\dagger$

\section{Results and discussion}

Values of $a_{\mathrm{mf}}$ and $b_{\mathrm{xv}}$ obtained by fitting to experimental isobars for $\mathrm{MeOH}$-water binary mixtures of different composition [molar fraction $x(\mathrm{MeOH})]$ are summarized in ESI, $\dagger$ Table S1. With increasing methanol molar fraction, the $a_{\mathrm{mf}}$ value also increases, from 0.19 up to $0.41 \mathrm{~J} \mathrm{~m}^{3} \mathrm{~mol}^{-1}$. At the same time, the fitting becomes less accurate as shown by the increase of the mean absolute error (MAE). Importantly, the ratio of $a_{\mathrm{mf}} / b_{\mathrm{xv}}$ is not constant but shows a parabolic shape. As a consequence, the application of the one-parameter variant of the QCE model to the methanol-water mixture might be problematic.

A similar dependence of the quality of the fitting on the composition has also been found for the DMSO-water binary system. ${ }^{30}$ However, while in DMSO-water the deviation increases with increasing water content, in the $\mathrm{MeOH}$-water mixture the quality of the fit becomes less satisfactory with increasing $x(\mathrm{MeOH})$, i.e. with decreasing water content. For DMSO-water these deviations had been attributed to the rather small clusters used. ${ }^{30}$ In the present case of $\mathrm{MeOH}$-water not only larger clusters but also a more extensive cluster set has been used.

In the case of neat water the cubic $w 8 c$ cluster has been shown to dominate at low temperatures, ${ }^{31,32}$ although neglecting it led to slightly more accurate isobars. To check the importance of this cluster type in binary $\mathrm{MeOH}$-water mixtures, the fitting to experimental isobars has been done with and without these $c 8$ clusters. Experimental isobars of neat water, neat $\mathrm{MeOH}$, and of the 30,60, $80 \mathrm{w} \% \mathrm{MeOH}$-water mixtures and those calculated by the QCE model using B3LYP-D3 results are shown in Fig. 2.

Compared with experiment a somewhat too small slope of the isobars - irrespective of the composition - is obtained. As ESI, $\dagger$ Table $\mathrm{S} 2$ shows, when cubic $c 8$ clusters are excluded, the values of $a_{\mathrm{mf}}$ and $b_{\mathrm{xv}}$ are only slightly changed. Isobars as well as the values of $a_{\mathrm{mf}}$ and $b_{\mathrm{xv}}$ obtained from M06-2X calculations differ only marginally from those based on B3LYP-D3 calculations (Tables S1 and S2, ESI $\dagger$ ).

The quality of the fit only marginally depends on whether cubic clusters are included in the set or not (Fig. 2). The numbers of clusters corresponding to a specific $x(\mathrm{MeOH})$ is shown in ESI, $\dagger$ Fig. S1. Although the number of clusters vary with $x$, overall the chosen cluster set should allow for a balanced description of the $\mathrm{MeOH}$-water mixture over the whole range of $\mathrm{MeOH}$ content.

Based on these optimal parameters $a_{\mathrm{mf}}$ and $b_{\mathrm{xv}}$ in the following, first interaction energies and distribution of the individual clusters considered for the $\mathrm{MeOH}$-water binary mixture will be presented. Second, thermodynamic properties (heat capacities $C_{\mathrm{p}}$, excess enthalpies, entropies, Gibbs free energies, and volumes of mixing, $H^{\mathrm{E}}, S^{\mathrm{E}}, G^{\mathrm{E}}$, and $V^{\mathrm{E}}$ ) derived therefrom will be compared with the corresponding experimental data as well as those obtained from previous calculations (molecular dynamics and Monte Carlo simulations).

\section{Cluster distribution in $\mathrm{MeOH}-\mathrm{H}_{2} \mathrm{O}$ binary mixture}

B3LYP-D3 as well as M06-2X interaction energies $E_{\text {int }}$ and Gibbs free energies of interaction $\Delta G_{\text {int }}^{298}$ for the whole cluster set used in the QCE procedure are presented in Table 1.

While interaction energies are strongly negative and approximately correlate with the number of hydrogen bonds, Gibbs free energies of interactions are invariably positive and do not show any correlation with the number of hydrogen bonds. 


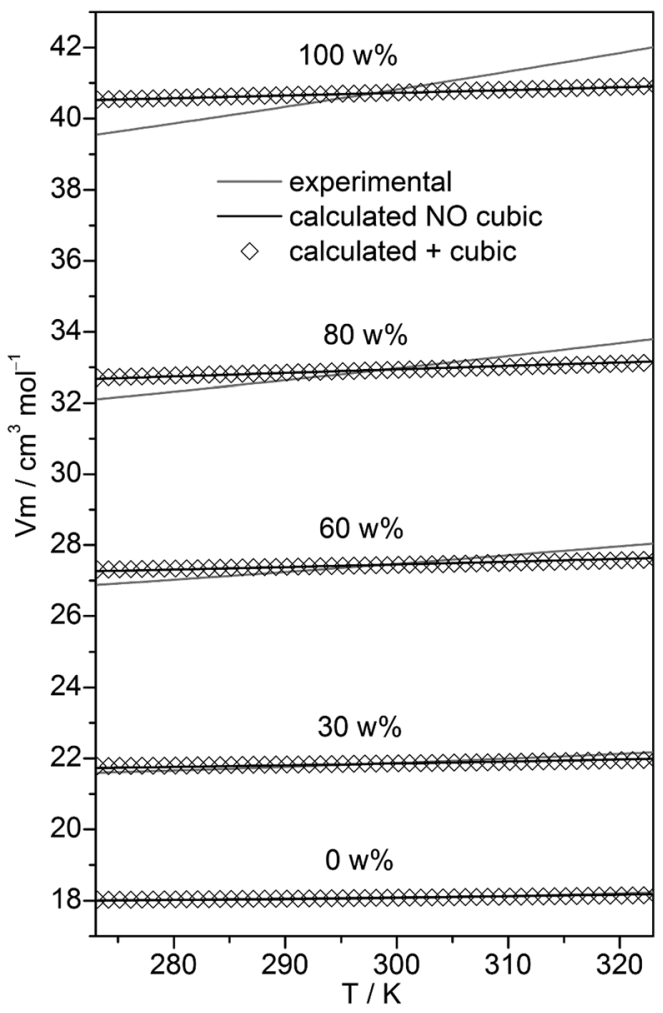

Fig. 2 Plot of experimental isobars ${ }^{68}$ of neat water, neat $\mathrm{MeOH}$ and 10 , $30,60,80 \mathrm{w} \% \mathrm{MeOH}$-water mixtures versus those obtained by the QCE model with and without inclusion of the cubic $c 8$ clusters.

According to the study of Thakkar et $a .^{21}$ dispersioncorrected density functionals work reasonably well for $\mathrm{MeOH}$ clusters compared with CCSD(T) results. Furthermore, M06-2X/ aug-cc-pVDZ interaction energies per molecule of both linear as well as cyclic $\mathrm{MeOH}$ clusters were found to be nearly identical to those obtained by MP2/aug-cc-pVTZ calculations. ${ }^{19}$ In contrast, B3LYP without dispersion corrections resulted in larger deviations. ${ }^{19}$ Comparison of the present B3LYP-D3/QZVP//TZVP and M06-2X/ aug-cc-pVTZ interaction energies with our previous MP2(fc)-CP/ $6-311++\mathrm{G}(\mathrm{d}, \mathrm{p})$ results indicate more negative $E_{\text {int }}$ values but nearly identical trends for both density functionals (Fig. S2, ESI $\dagger$ ). Moreover, B3LYP-D3 calculated interaction energies for the full cluster set considered in this paper (Table 1) are in close agreement with the corresponding M06-2X/aug-cc-pVTZ values $\left(R^{2}=0.998\right.$, Fig. S3, ESI +$)$. Thus, we are confident that the functionals used are appropriate for this study.

The population (based on the B3LYP-D3 calculations) of pure water, pure methanol as well as mixed clusters without further distinction of their composition at three different temperatures $(273,298$, and $323 \mathrm{~K})$ is displayed in Fig. 3.

Irrespective of the temperature mixed clusters dominate over a wide range of the composition of the binary $\mathrm{MeOH}-$ water system $(\geq 60 \%$ in the range $x(\mathrm{MeOH})=0.1$ to 0.8$)$. Only a slight decrease of the contribution of mixed clusters with increasing temperature is found (Fig. 3). It is interesting to note that NMR relaxation time measurements of $\mathrm{MeOH}$-water mixtures have indicated that at low temperatures $T_{\mathrm{k}}<245 \mathrm{~K}$

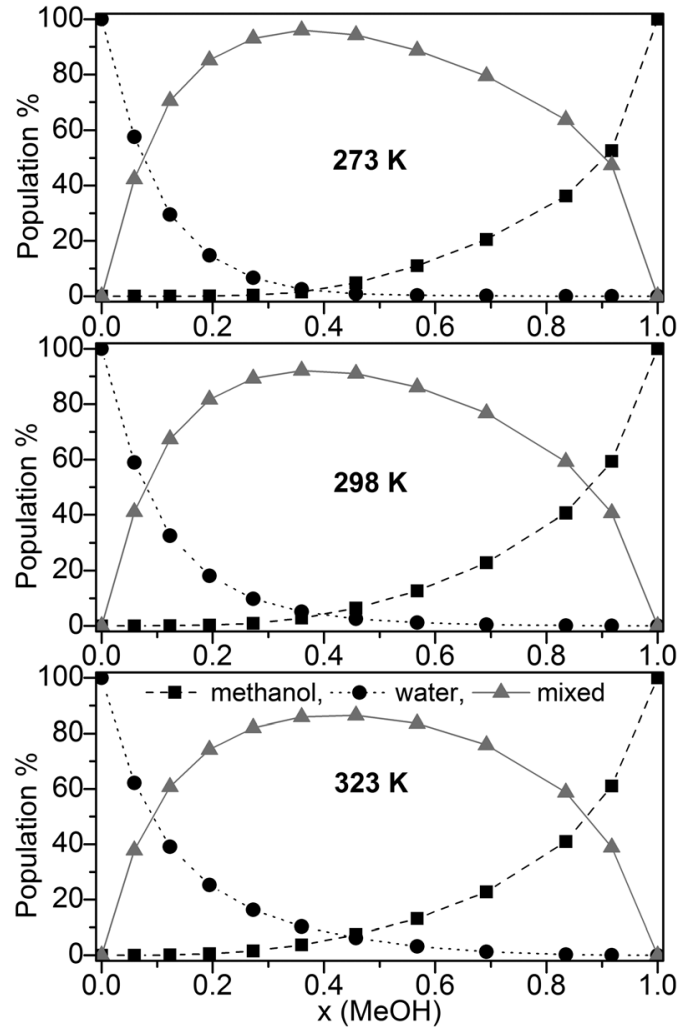

Fig. 3 Population (\%) of $\mathbf{a r e}$ methanol clusters, $\bullet$ pure water cluster, $\triangle$ mixed $\mathrm{MeOH}$-water clusters at $273 \mathrm{~K}, 298 \mathrm{~K}$, and $323 \mathrm{~K}$ based on the B3LYP-D3 calculations.

clusters between the same species prevail while above $T_{\mathrm{k}}$ mixed clusters are preferred. ${ }^{85}$

Since the lowest temperature considered here $(T=273 \mathrm{~K})$ is well above $T_{\mathrm{k}}$ the predominance of mixed clusters in the intermediate molar fraction region is in line with these experimental findings. Although we have taken into account only clusters up to 11 molecules, our result obtained for the maximum population of mixed clusters at $x=0.365(273 \mathrm{~K})$ is in line with the mass spectroscopy experiments of Wakisaka. ${ }^{5,8}$ From these experiments it had been concluded that above $x(\mathrm{MeOH})=$ 0.375 the self-association of alcohol clusters becomes more preferred with increasing $x(\mathrm{MeOH}) .{ }^{5,8}$ The gross populations of pure and mixed clusters based on M06-2X/aug-cc-pVTZ calculations are quite similar to those obtained by B3LYP-D3 (Fig. S4, ESI $\dagger$ ). The most notable difference concerns mixed clusters which show lower populations over the whole range of $x(\mathrm{MeOH})$ than those based on B3LYP-D3 calculations $[<70 \%$ (M06-2X) at $T=298 \mathrm{~K}$ compared with up to $90 \%$ (B3LYP-D3, Fig. 3)]. For DMSO-water binary system a similar distribution of pure water, pure DMSO, and mixed clusters had been found. ${ }^{30}$ However, the drop and/or rise of the pure clusters is less steep in DMSOwater than in $\mathrm{MeOH}-$ water.

For instance, $\sim 60 \%$ pure water clusters at $x$ (DMSO) $=0.2$ and $\sim 60 \%$ pure DMSO clusters at $x$ (DMSO) $=0.8$ had been calculated ${ }^{30}$ compared with $\sim 20 \%$ pure water clusters at $x(\mathrm{MeOH})=0.2$ and $\sim 40 \%$ pure $\mathrm{MeOH}$ clusters at $x(\mathrm{MeOH})=0.8$ (Fig. 3). Consequently, the population of the mixed DMSO-water clusters is 
significantly lower $(\leq 60 \%)^{30}$ than that of mixed $\mathrm{MeOH}$-water clusters.

The population of the various cluster classes irrespective of their composition (based on the B3LYP-D3 calculations) is presented in Fig. 4a (cubic $c 8$ clusters included) and Fig. 4b (populations with cubic $c 8$ clusters neglected).

The results in Fig. 4a show that only some of the used clusters are important to consider when including cubic clusters. These are the five- and six-membered monocyclic structures with only one ring, the 8-membered cubic clusters and the $s 9$ and $s 11$ spiro-type clusters. In line with previous findings for neat water $^{32,33}$ the population of cubic $c 8$ clusters decreases with increasing temperature. Nevertheless, this cluster type by far is dominating up to $x(\mathrm{MeOH})=0.7(273 \mathrm{~K})$, and $x(\mathrm{MeOH})=0.5$ $(323 \mathrm{~K})$. Since these clusters contain at least 4 water molecules it is not surprising that at higher $\mathrm{MeOH}$ contents their population drops significantly while the populations of monocyclic clusters ( $r 5$ and especially $r 6$ ) where there is no such restriction with respect to the number of water molecules increase substantially at high $x(\mathrm{MeOH})$. The presence of such cyclic structures in liquids capable of forming hydrogen bonds has been corroborated by experimental studies (soft X-ray emission ${ }^{86}$ and X-ray absorption augmented by DFT calculations $\left.{ }^{87}\right)$. Especially at lower temperatures the spiro-type cluster $s 11(6-6)$ is quite important for mixtures with relatively high $\mathrm{MeOH}$ content (maximum of $\sim 25 \%$ at $x(\mathrm{MeOH}) \sim 0.8$ and $T=273$ K, Fig. 4 ). The populations of $s 9$ spiro type clusters are fairly constant over the whole composition of the $\mathrm{MeOH}$-water mixture at low temperatures; at $T=323 \mathrm{~K}$ this cluster type is also populated (10-20\%) especially in the water-rich region.

If cubic clusters are neglected in the QCE model (Fig. 4b), the spiro-type clusters $s 11(6-6)$ and especially $s 9(5-5)$ dominate in the water-rich region at lower temperatures (up to $x(\mathrm{MeOH})=$ 0.6 at $T=273 \mathrm{~K}$ ); with increasing temperature their contribution decreases from $\sim 50 \%(T=273 \mathrm{~K})$ to $\sim 35 \%(T=323 \mathrm{~K})$ for neat water. Since at least one water molecule is required for the spiro motif, the population steadily decreases with increasing $\mathrm{MeOH}$ content. In contrast to spiro clusters, the populations of monocyclic rings ( $r 5$ and $r 6$ ) steadily increase with $x(\mathrm{MeOH})$. As a consequence, neat $\mathrm{MeOH}$ is almost exclusively (>90\%) composed of five- and six-membered ring clusters. Since cubic clusters require at least four water molecules, this result holds irrespective whether $c 8$ clusters are included or not in the cluster set used to describe the $\mathrm{MeOH}$-water system. Interestingly, seven-membered monocyclic rings $r 7$ are not negligible at higher temperatures and low $\mathrm{MeOH}$ content (Fig. 4b).

Populations of individual clusters, i.e. distinguished by composition, are plotted in Fig. 5a (including cubic clusters) and Fig. 5b (neglecting cubic clusters). Dominating clusters are the cubic, spiro ( $s 9$ and $s 11$ ), and ring-type structures while
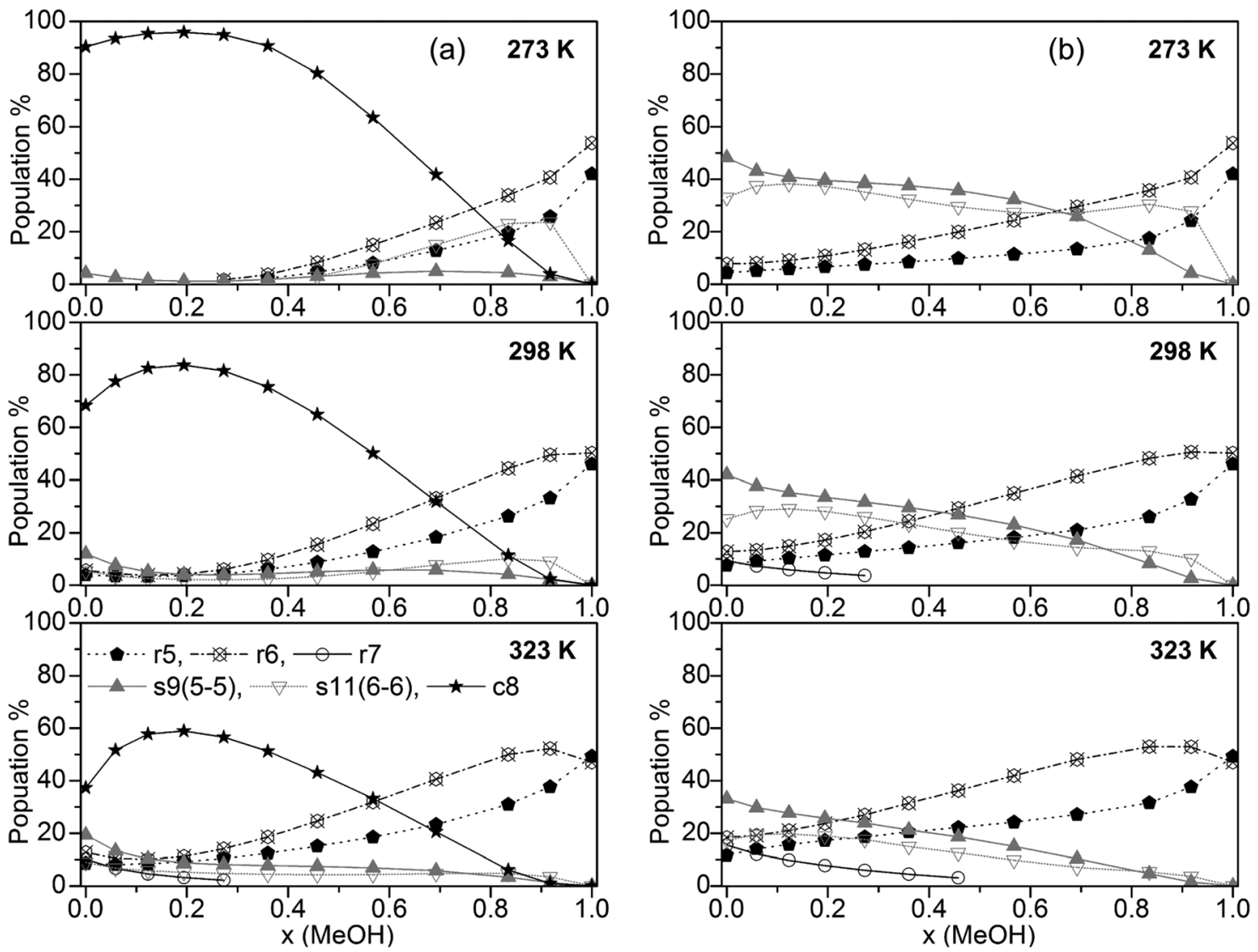

Fig. 4 Plot of the population of the cluster classes (a) including and (b) excluding cubic c 8 clusters (for clarity, only clusters with populations $>10 \%$ are shown). 
book, lasso and bicyclic clusters are of minor importance. Concerning cubic clusters, for neat water the $w 8 c$ cluster is by far dominating, $\sim 70 \%$ at $T=273$ and $298 \mathrm{~K}, \sim 40 \%$ at $T=$ $323 \mathrm{~K}$. With increasing $\mathrm{MeOH}$ content the population of this cluster drops quite quickly $(\sim 10 \%$ for $x(\mathrm{MeOH})=0.2)$. In the water-rich region with $x(\mathrm{MeOH})<0.3$ the $m 1 w 7 c$ structure becomes the dominating cubic cluster with a relatively sharp maximum at $x(\mathrm{MeOH}) \sim 0.15$. In the intermediate region, $x(\mathrm{MeOH})=0.2$ to 0.7 the largest population is obtained for $m 3 w 5 c$ and, to a lesser extent, for $m 4 w 4 c$. Especially at lower temperatures $(T=273$ and $298 \mathrm{~K})$ and low $\mathrm{MeOH}$ content $(x(\mathrm{MeOH})=0.1-0.4)$ the $m 2 w 6 c$ cluster is significantly populated. An increase of the temperature results in a decrease of the populations of these cubic clusters. With respect to spiro-type clusters, in neat water and at very low $\mathrm{MeOH}$ content $(x \leq 0.15)$ only $w 9 s$ is significantly populated with the population increasing at higher temperatures at the expense of $w 8 c$. The only other spiro-type cluster is $m 10 w 1 s$ at $T=273 \mathrm{~K}$ for $x(\mathrm{MeOH})>0.5$ (maximum of $20 \%$ at $x(\mathrm{MeOH})=\sim 0.9$ ). While monocyclic ring structures consisting solely of water molecules $(w 6 r, w 7 r)$ are of minor importance $(<15 \%$ at $T=323 \mathrm{~K}$ and even less at lower temperatures), the analogous $\mathrm{MeOH}$ clusters $m 5 r$ and $m 6 r$ become increasingly important with increasing $\mathrm{MeOH}$ content. As mentioned above, neat $\mathrm{MeOH}$ can almost exclusively be described by these two cluster types. At $T=323 \mathrm{~K}$ the dominant cluster in the region $x(\mathrm{MeOH})=0.6-0.8$ is $m 5 w 1 r$. The analogous plot obtained with M06-2X for $T=298 \mathrm{~K}$ is shown in Fig. S5 (ESI $\dagger$ ). Similar to the B3LYP-D3 results, the dominating cluster types at low $\mathrm{MeOH}$ content are the cubic clusters $w 8 c$ and $m 1 w 7 c$ and at high $\mathrm{MeOH}$ content the $m 6 r$ ring structure. In the range $x(\mathrm{MeOH})=0.6-0.9$ the cyclic cluster $m 5 w 1 r$ is already significantly populated (10-20\%) at $T=298 \mathrm{~K}$. Interestingly, in contrast to the B3LYP-D3 results, the five-membered cyclic $m 5 r$ cluster does not show any substantial population at $T=298 \mathrm{~K}$.

Fig. 5b presents cluster populations obtained when cubic clusters are excluded. In the $\mathrm{MeOH}-$ rich region $(x(\mathrm{MeOH})>$ 0.8 ) where cubic clusters are of minor importance, the cluster distribution is quite similar to that obtained with cubic clusters included. The most important contributions are due to the fiveand six-membered monocyclic rings $m 5 r, m 6 r$, and $m 5 w 1 r$. Of course, for neat $\mathrm{MeOH}$ the population of this latter cluster drops to 0 (Fig. 5b). For neat water and low $\mathrm{MeOH}$ content a significant increase of the spiro-type water clusters $w 9 s$ and $w 11 s$ can be seen. At higher temperatures the contributions of these clusters decrease in favor of monocyclic rings $w 6 r$ and $w 5 r$ (at $T=323 \mathrm{~K}$ ). This is in agreement with Wakisaka's results, ${ }^{8}$ that self-associated clusters are formed predominantly at low molar fraction (water clusters) and high molar fraction $(x \geq 0.375$, methanol clusters).
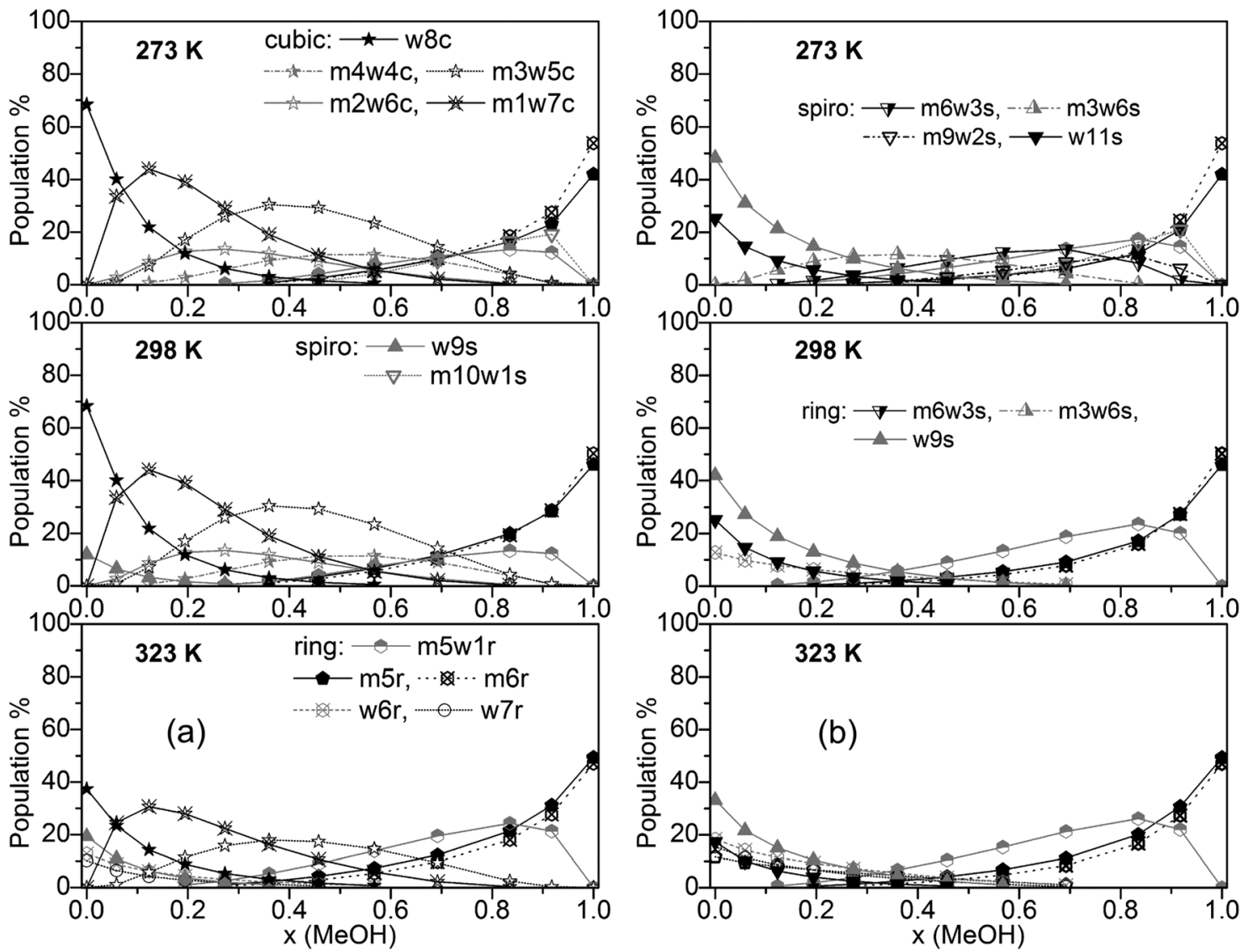

Fig. 5 Plot of individual cluster distributions (a) including and (b) excluding cubic c 8 clusters (for clarity, only clusters with populations $>8 \%$ are shown). 
Table 2 Comparison of the calculated excess thermodynamic quantities $\left(H^{\mathrm{E}}, S^{\mathrm{E}}, G^{\mathrm{E}}\right)$ with data obtained from other experimental and theoretical studies. Units are $\mathrm{kJ} \mathrm{mol}^{-1}$ and $\mathrm{J} \mathrm{K}^{-1} \mathrm{~mol}^{-1}$

\begin{tabular}{|c|c|c|c|c|c|c|}
\hline$x(\mathrm{MeOH})$ & & Exp. $^{67,88,91}$ & $\begin{array}{l}\mathrm{MD} / \\
2 \mathrm{PT}^{56}\end{array}$ & $\begin{array}{l}\text { OPLS/ } \\
\text { TIP4P } 64\end{array}$ & $\begin{array}{l}\text { QCE } \\
\text { B3LYP-D3 }\end{array}$ & $\begin{array}{l}\text { QCE } \\
\text { M06-2X }\end{array}$ \\
\hline \multirow[t]{3}{*}{0.05} & $H^{\mathrm{E}}$ & -0.57 & -0.18 & -0.25 & -0.81 & -0.40 \\
\hline & $S^{\mathrm{E}}$ & -2.48 & -0.70 & -1.01 & -2.91 & -2.02 \\
\hline & $G^{\mathrm{E}}$ & 0.17 & 0.06 & 0.05 & 0.11 & 0.20 \\
\hline \multirow[t]{3}{*}{0.27} & $H^{\mathrm{E}}$ & -0.88 & -0.66 & -0.32 & -2.18 & -0.49 \\
\hline & $S^{\mathrm{E}}$ & -3.93 & -3.31 & -3.42 & -8.44 & -4.25 \\
\hline & $G^{\mathrm{E}}$ & 0.29 & 0.37 & 0.70 & 0.42 & 0.78 \\
\hline \multirow[t]{3}{*}{0.54} & $H^{\mathrm{E}}$ & -0.79 & -0.82 & -0.32 & -1.67 & -0.17 \\
\hline & $S^{\mathrm{E}}$ & -3.69 & -3.93 & -3.50 & -7.45 & -3.84 \\
\hline & $G^{\mathrm{E}}$ & 0.31 & 0.42 & 0.72 & 0.63 & 0.97 \\
\hline \multirow[t]{3}{*}{0.70} & $H^{\mathrm{E}}$ & -0.61 & -0.73 & -0.22 & -1.06 & 0.16 \\
\hline & $S^{\mathrm{E}}$ & -2.89 & -3.39 & -2.77 & -5.48 & -2.99 \\
\hline & $G^{\mathrm{E}}$ & 0.25 & 0.35 & 0.61 & 0.61 & 1.05 \\
\hline
\end{tabular}

Calculated thermodynamic functions for methanol-water binary liquid mixtures

Based on the QCE calculations, the following thermodynamic functions are available from the canonical partition function according to eqn (22)-(29) in ref. 33 for the different temperatures and compositions: internal energy, enthalpy, entropy, Gibbs free energy, Helmholtz free energy as well as second derivatives of the partition function, like constant pressure and constant volume heat capacities.

In Table 2 we compare the experimental excess enthalpies, entropies, and Gibbs free energies of mixing ${ }^{64,65,67,68,88-91}$ with those calculated by the QCE model as well as those obtained from a molecular dynamics simulation/two-phase thermodynamics $(\mathrm{MD} / 2 \mathrm{PT})^{56}$ for different compositions of the $\mathrm{MeOH}$-water system.

The excess enthalpies of mixing $H^{\mathrm{E}}$ (eqn (5)) (Fig. 6a) and the excess entropy of mixing $S^{\mathrm{E}}$ (eqn (6)) (Fig. 6b) obtained by the QCE calculations with and without inclusion of cubic clusters are plotted against experimental data. ${ }^{89,90}$

$$
H^{\mathrm{E}}(x)=H(x)-\left[H\left(\mathrm{H}_{2} \mathrm{O}_{\mathrm{liq}}\right) \times(1-x)+H\left(\mathrm{MeOH}_{\mathrm{liq}}\right) \times x\right]
$$

The enthalpy values $H$ are taken from the PEACEMAKER output, where $H\left(\mathrm{H}_{2} \mathrm{O}_{\text {liq }}\right)$ and $H\left(\mathrm{MeOH}_{\text {liq }}\right)$ are the values for $x=$ 0.0 and $x=100.0$, respectively. Compared with experiment, the values of $H^{\mathrm{E}}$ are too negative but the minima of the curves occur approximately at the same molar fraction $(x \sim 0.36)$. In contrast, $\mathrm{MD} / 2 \mathrm{PT}^{56}$ with the SPC/E model for water (which gave the best results) and even more so OPLS/TIP4P ${ }^{64}$ calculations resulted in less negative $H^{\mathrm{E}}$ values than experiment (Table 2). Neglecting cubic clusters leads to considerably less negative excess enthalpies of mixing $H^{\mathrm{E}}$, i.e. values closer to experiment but with a minimum shifted to much higher $\mathrm{MeOH}$ content, $x(\mathrm{MeOH}) \sim 0.8$ (Fig. 6a). The excess entropy of mixing $S^{\mathrm{E}}$ is computed according to eqn (6).

$$
\begin{aligned}
S^{\mathrm{E}}(x)= & S(x)-\left[S\left(\mathrm{H}_{2} \mathrm{O}_{\text {liq }}\right) \times(1-x)+S\left(\mathrm{MeOH}_{\text {liq }}\right) \times x\right] \\
& +R[x \ln (x)+(1-x) \ln (1-x)]
\end{aligned}
$$

Similar to the excess enthalpies of mixing too negative values for $S^{\mathrm{E}}$ are obtained when cubic clusters are included. Without cubic clusters nearly perfect agreement with experiment is obtained (Fig. 6b). While OPLS/TIP4P ${ }^{64}$ calculations resulted in less negative $S^{\mathrm{E}}$ values than experiment, $\mathrm{MD} / 2 \mathrm{PT} S^{\mathrm{E}}$ values
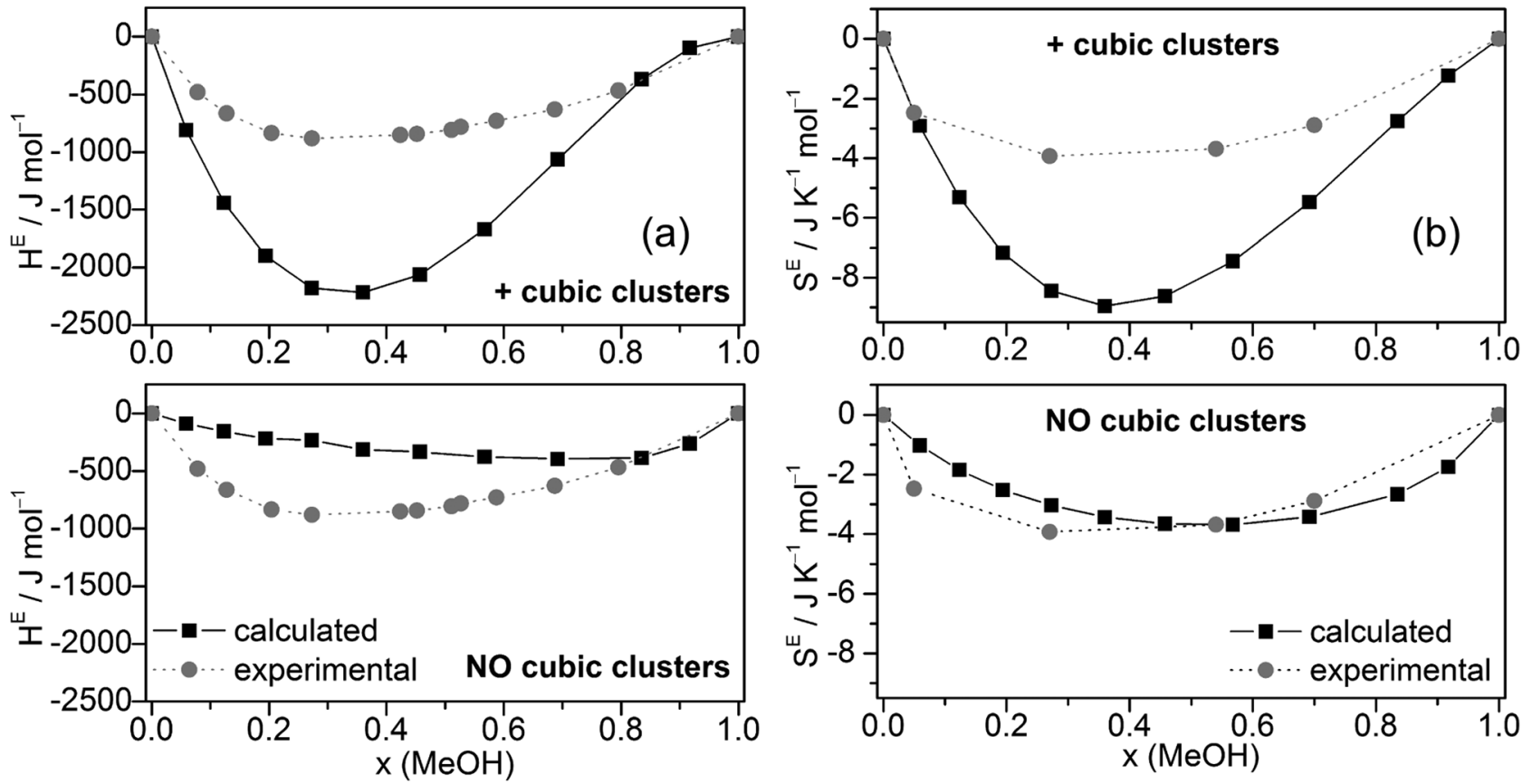

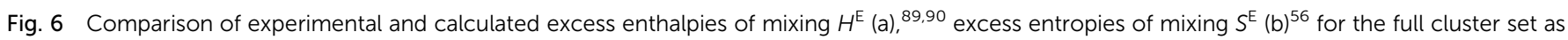
well as the cluster set without the cubic c 8 clusters at different molar ratios. 

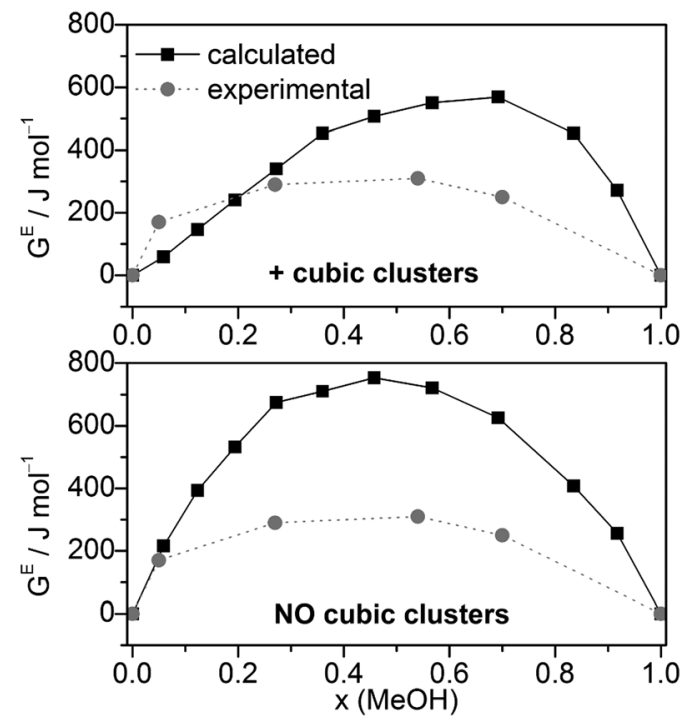

Fig. 7 Comparison of experimental ${ }^{56}$ and calculated excess Gibbs free energies of mixing $G^{E}$ for the full cluster set as well as the cluster set without the cubic $c 8$ clusters at different molar ratios $(T=298 \mathrm{~K})$.
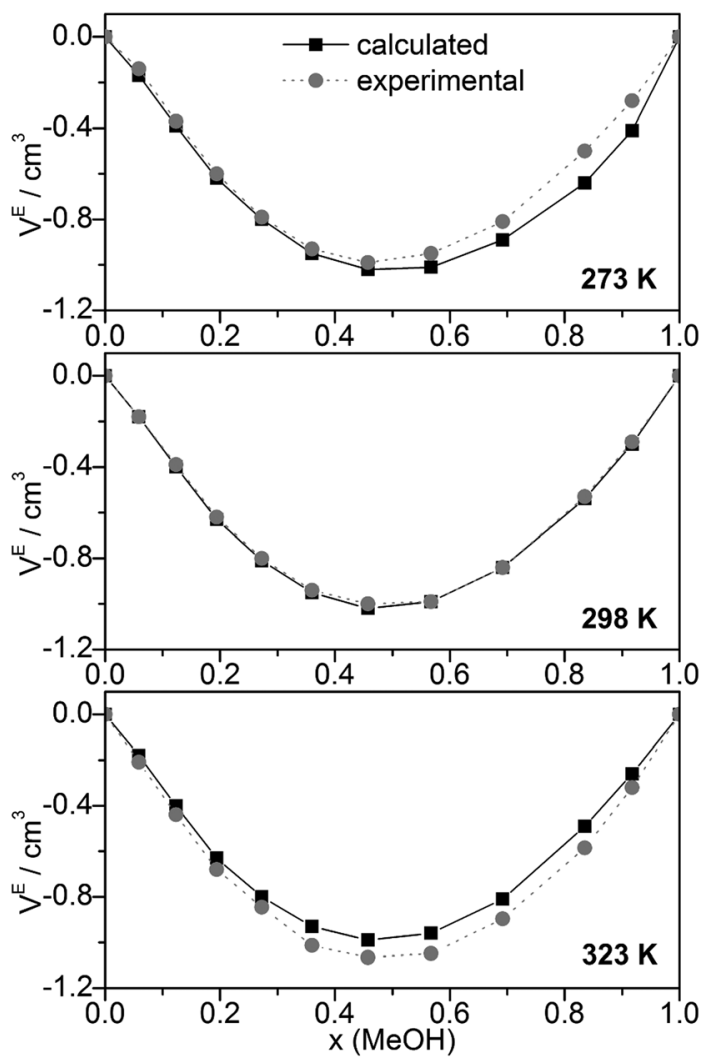

Fig. 8 Comparison of experimental ${ }^{68}$ and calculated excess volumes of mixing $V^{E}$.

were less negative than experimental data at low and more negative at high $x(\mathrm{MeOH})$, see Table $2 .^{56}$

Combining $H^{\mathrm{E}}$ and $S^{\mathrm{E}}$ results to Gibbs free energies of mixing via $G^{\mathrm{E}}=H^{\mathrm{E}}-T \cdot S^{\mathrm{E}} . G^{\mathrm{E}}$ values agree relatively well with the experimental data (Fig. 7), although more positive. Compared with the $G^{\mathrm{E}}$ values obtained by $\mathrm{MD} / 2 \mathrm{PT}^{56}$ or OPLS/TIP4P $\mathrm{P}^{64}$ the corresponding QCE data are more and less, respectively, positive except at $x(\mathrm{MeOH})=0.05$ (Table 2).

Excess thermochemical quantities of mixing obtained by the QCE model using M06-2X interaction energies and vibrational frequencies show the following (Table 2 and Fig. S6, ESI $\dagger$ ): the $H^{\mathrm{E}}$ values are less negative than those obtained with B3LYP-D3 or even positive in the methanol rich region $(x>0.7) ; S^{\mathrm{E}}$ values are in quite good agreement with experimental values especially in the case of the full cluster set. As a consequence, the $G^{\mathrm{E}}$ values are more positive than the experimental ones or those calculated by the B3LYP-D3 functional.

The calculated dependence of the excess Gibbs free energy of mixing for the only other binary solvent system treated so far by the QCE model (DMSO-water) closely matches the experimental curve, especially the minimum at $x(\mathrm{DMSO}) \sim 0.4$. In contrast to $\mathrm{MeOH}$-water, for DMSO-water $G^{\mathrm{E}}$ is negative over the whole range of $x$ (DMSO). However, similar to the $\mathrm{MeOH}-$ water results, the QCE model yields for DMSO-water also too positive $G^{\mathrm{E}}$ values compared with experiment. ${ }^{30}$

Other quantities which can be compared with experiment are excess volumes of mixing $V^{\mathrm{E}}$ (Fig. 8), heat capacities $C_{\mathrm{p}}$ (Fig. 9), and excess heat capacities of mixing $C_{\mathrm{p}}^{\mathrm{E}}$ (Fig. S7, ESI $\dagger$ ). $V^{\mathrm{E}}$ and $C_{\mathrm{p}}^{\mathrm{E}}$ were calculated in analogy to eqn (5). Since the parameter fits have been carried out to get good agreement between experimental and calculated molar volumes $\left(V_{\mathrm{m}}\right)$, the calculated $V^{\mathrm{E}}$ values agree nearly perfectly with the corresponding experimental data ${ }^{68}$ as well as those obtained from a Monte Carlo simulation of TIP4P water and OPLS MeOH mixtures. ${ }^{63}$

The heat capacities $C_{\mathrm{p}}$ or the excess heat capacities of mixing $C_{\mathrm{p}}^{\mathrm{E}}$ are the least satisfactorily reproduced quantities by the QCE calculations, irrespective of whether B3LYP-D3 or M06-2X results were used (Fig. 9, Fig. S7 and S8, ESI $\dagger$ ). Such discrepancies
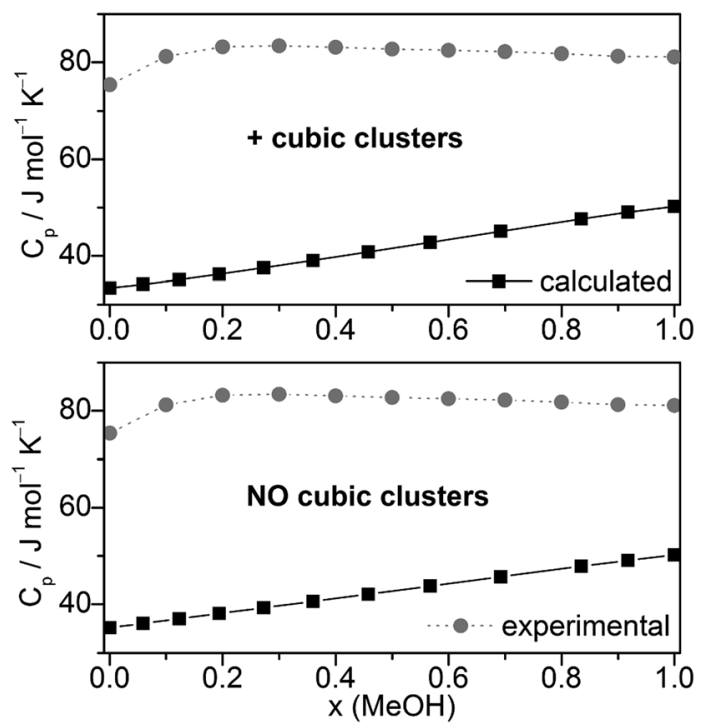

Fig. 9 Comparison of experimental ${ }^{67,92,93}$ and calculated heat capacities $C_{\mathrm{p}}$ at $T=298.15 \mathrm{~K}$. 
had already been noticed in the original QCE publication. $^{23}$ One possible explanation of this deviation is the application of harmonic oscillator approximation even for the low frequency vibrations. In line with this, the vibrational contribution $\left(C_{\mathrm{p}, \mathrm{vib}}\right)$ obtained from the vibrational partition function possess the largest amount of contribution to $C_{\mathrm{p}}$, also in accordance with ref. 33 .

Furthermore, it should be considered that the heat capacity is the second derivative of the partition function. Thus it is affected more by the applied approximations in the model than the other first derivative quantities.

\section{Conclusions}

The quantum cluster equilibrium model has been applied for the binary mixture of $\mathrm{MeOH}$-water. Structures and interaction energies for a set of 93 clusters of different size, composition as well as class (chain, monocyclic rings, spiro, lasso, bicyclic, cubic) have been calculated by density functional theory (B3LYP-D3/QZVP and M06-2X/aug-cc-pVTZ including counterpoise BSSE corrections). B3LYP-D3 results in somewhat more negative interaction energies but the observed trend closely matches that obtained by M06-2X. The two fitting parameters $a_{\mathrm{mf}}$ and $b_{\mathrm{xv}}$ used in the QCE model were obtained by fitting to experimental isobars of $\mathrm{MeOH}$-water binary mixtures with varying composition. Isobars based on B3LYP-D3 and M06-2X calculations were quite similar. With increasing $\mathrm{MeOH}$ content an increasing deviation between calculated and experimental isobars was found. Cluster distributions calculated by the QCE model using either B3LYP-D3 or M06-2X were quite similar with one notable exception: while the monocyclic ring-type clusters $m 5 r$ and $m 6 r$ both were found quite significant at high $\mathrm{MeOH}$ content with B3LYP-D3, only $m 6 r$ showed a substantial population (50-100\% in the range $x(\mathrm{MeOH})=0.7-1.0)$ based on M06-2X interaction energies and vibrational frequencies. Cubic $c 8$ cluster structures like $w 8 c$ or $m 1 w 7 c$ were found to dominate at low $\mathrm{MeOH}$ content whereas monocyclic ring structures, especially $m 6 r$ were the most important clusters for $x(\mathrm{MeOH})>0.8$. In the intermediate region, $x(\mathrm{MeOH}) \sim 0.4$ to 0.7 the cubic cluster $m 3 w 5 c$ is the dominant species. With increasing temperature the populations of these clusters decrease with a concomitant increase of other cluster populations, e.g. the monocyclic ring structure $m 5 w 1 r$.

Compared with experiment the calculated (B3LYP-D3) excess enthalpies of mixing $H^{\mathrm{E}}$ of methanol-water are somewhat too negative, those based on M06-2X are less negative and show larger overall deviations from the experimental curve in the methanol rich region. Excess entropies of mixing $S^{\mathrm{E}}$ are also too negative with B3LYP-D3 while those based on M06-2X nearly perfectly match the experimental $S^{\mathrm{E}} v s . x(\mathrm{MeOH})$ curve. Calculated excess Gibbs free energies of mixing $G^{\mathrm{E}}$ by either density functional are more positive than experimental values With respect to previous molecular dynamics simulations of the $\mathrm{MeOH}$-water mixtures, ${ }^{56,64}$ the QCE model based on B3LYP-D3 calculations consistently results in excess enthalpies $H^{\mathrm{E}}$ and especially entropies $S^{\mathrm{E}}$ of mixing which are more negative. Excess Gibbs free energies of mixing $G^{\mathrm{E}}$ are slightly more positive than the MD/2PT results of Pascal and Goddard ${ }^{56}$ and slightly less positive than or even equal to the MD results of Tanaka and Gubbins. ${ }^{64}$ The calculated excess volumes of mixing compare well with experiment. Significant deviations between calculated and experimental heat capacities $C_{\mathrm{p}}$ and excess heat capacity of mixing $C_{\mathrm{p}}^{\mathrm{E}}$ were found.

\section{Acknowledgements}

The computations were run on the Hungarian HPC infrastructure (NIIF Institute, Hungary) and on computational facilities at Karl-Franzens University of Graz and at Graz University of Technology. The authors thank Prof. B. Kirchner and S.B.C. Lehmann for the discussions regarding the PEACEMAKER program. Financial support of the SROP-4.2.2.A-11/1/KONV2012-0065 project is gratefully acknowledged. The work was also supported by the Scholarship program of the Aktion Österreich-Ungarn.

\section{Notes and references}

1 R. Mecke and H. Kempter, Naturwissenschaften, 1939, 27, 583.

2 Y. Marcus, Solvent Mixtures, Properties and Selective Solvation, CRC Press, 2002.

3 A. Ben-Naim, J. Phys. Chem. B, 2007, 111, 2896.

4 C. Reichardt, Solvents and Solvent Effects in Organic Chemistry, Wiley-VCH Verlag, Weinheim, 3rd edn, 2003.

5 A. Wakisaka and T. Iwakami, J. Mol. Liq., 2014, 189, 44.

6 A. Wakisaka and K. Matsuura, J. Mol. Liq., 2006, 129, 25.

7 A. Wakisaka, S. Mochizuki and H. Kobara, J. Solution Chem., 2004, 33, 721.

8 A. Wakisaka, S. Komatsu and Y. Usui, J. Mol. Liq., 2001, 90, 175.

9 A. Wakisaka and T. Ohki, Faraday Discuss., 2005, 129, 231.

10 A. Wakisaka and Y. Yamamoto, J. Chem. Soc., Chem. Commun., 1994, 2105.

11 S. Kunsagi-Mate and K. Iwata, Chem. Phys. Lett., 2009, 473, 284.

12 S. Kunsagi-Mate and K. Iwata, J. Solution Chem., 2013, 42, 165.

13 A. Mandal, M. Prakash, R. M. Kumar, R. Parthasarathi and V. Subramanian, J. Phys. Chem. A, 2010, 114, 2250.

14 G. Matisz, A.-M. Kelterer, W. M. F. Fabian and S. Kunsagi-Mate, J. Phys. Chem. A, 2011, 115, 10556.

15 V. S. Bryantsev, M. S. Diallo, A. C. T. van Duin and W. A. Goddard, J. Chem. Theory Comput., 2009, 5, 1016.

16 R. Wieczorek, L. Haskamp and J. J. Dannenberg, J. Phys. Chem. A, 2004, 108, 6713.

17 R. N. Barnett and U. Landman, J. Phys. Chem. A, 1997, 101, 164.

18 S. L. Boyd and R. J. Boyd, J. Chem. Theory Comput., 2007, 3, 54 .

19 P. Golub, I. Doroshenko and V. Pogorelov, Phys. Lett. A, 2014, 378, 1937. 
20 F. C. Hagemeister, C. J. Gruenloh and T. S. Zwier, J. Phys. Chem. A, 1998, 102, 82.

21 S. Kazachenko, S. Bulusu and A. J. Thakkar, J. Chem. Phys., 2013, 138, 224303.

22 F. Weinhold, J. Chem. Phys., 1998, 109, 367.

23 F. Weinhold, J. Chem. Phys., 1998, 109, 373.

24 R. Ludwig and F. Weinhold, J. Chem. Phys., 1999, 110, 508.

25 R. Ludwig and F. Weinhold, Phys. Chem. Chem. Phys., 2000, $2,1613$.

26 R. Ludwig and F. Weinhold, Z. Phys. Chem., 2002, 216, 659.

27 R. Ludwig, Phys. Chem. Chem. Phys., 2002, 4, 5481.

28 P. Borowski, J. Jaroniec, T. Janowski and K. Wolinski, Mol. Phys., 2003, 101, 1413.

29 R. Ludwig, ChemPhysChem, 2007, 8, 938.

30 A. Lenz and L. Ojamae, J. Chem. Phys., 2009, 131, 134302.

31 S. B. C. Lehmann, C. Spickermann and B. Kirchner, J. Chem. Theory Comput., 2009, 5, 1640.

32 S. B. C. Lehmann, C. Spickermann and B. Kirchner, J. Chem. Theory Comput., 2009, 5, 1650.

33 B. Kirchner, C. Spickermann, S. B. C. Lehmann, E. Perlt, J. Langner, M. von Domaros, P. Reuther, F. Uhlig, M. Kohagen and M. Brüssel, Comput. Phys. Commun., 2011, 182, 1428.

34 M. Brüssel, E. Perlt, M. von Domaros, M. Brehm and B. Kirchner, J. Chem. Phys., 2012, 137, 164107.

35 R. Ludwig, ChemPhysChem, 2005, 6, 1369.

36 R. Ludwig, ChemPhysChem, 2005, 6, 1376.

37 G. Matisz, W. M. F. Fabian, A.-M. Kelterer and S. Kunsagi-Mate, THEOCHEM, 2010, 956, 103.

38 G. Matisz, A.-M. Kelterer, W. M. F. Fabian and S. Kunsagi-Mate, J. Phys. Chem. B, 2011, 115, 3936.

39 M. Huelsekopf and R. Ludwig, J. Mol. Liq., 2000, 85, 105.

40 R. Ludwig, F. Weinhold and T. C. Farrar, Mol. Phys., 1999, 97, 465.

41 R. Ludwig, F. Weinhold and T. C. Farrar, Mol. Phys., 1999, 97, 479.

42 M. Huelsekopf and R. Ludwig, J. Mol. Liq., 2002, 98, 163.

43 M. A. Wendt, F. Weinhold and T. C. Farrar, J. Chem. Phys., 1998, 109, 5945.

44 M. J. Hansen, M. A. Wendt and F. Weinhold, Mol. Phys., 2003, 101, 1147.

45 R. Ludwig, F. Weinhold and T. C. Farrar, Ber. Bunsen-Ges., 1998, 102, 197.

46 R. Ludwig, F. Weinhold and T. C. Farrar, Ber. Bunsen-Ges., 1998, 102, 205.

47 R. Ludwig, F. Weinhold and T. C. Farrar, J. Phys. Chem. A, 1997, 101, 8861.

48 R. Ludwig, O. Reis, R. Winter, F. Weinhold and T. C. Farrar, J. Phys. Chem. B, 1998, 102, 9312.

49 M. Huelsekopf and R. Ludwig, Magn. Reson. Chem., 2001, 39, S127.

50 R. Ludwig, J. Behler, B. Klink and F. Weinhold, Angew. Chem., Int. Ed., 2002, 41, 3199.

51 J. Friedrich, E. Perlt, M. Roatsch, C. Spickermann and B. Kirchner, J. Chem. Theory Comput., 2011, 7, 843.
52 C. Spickermann, E. Perlt, M. von Domaros, M. Roatsch, J. Friedrich and B. Kirchner, J. Chem. Theory Comput., 2011, 7, 868.

53 E. Perlt, J. Friedrich, M. von Domaros and B. Kirchner, ChemPhysChem, 2011, 12, 3474.

54 F. Weinhold, J. Phys. Chem. B, 2014, 118, 7792.

55 M. Brüssel, E. Perlt, S. B. C. Lehmann, M. von Domaros and B. Kirchner, J. Chem. Phys., 2011, 135, 194113.

56 T. A. Pascal and W. A. Goddard, J. Phys. Chem. B, 2012, 116, 13905.

57 L. Vlcek and I. Nezbeda, J. Mol. Liq., 2007, 131, 158.

58 B. Hribar-Lee and K. A. Dill, Acta Chim. Slov., 2006, 53, 257.

59 D. P. Geerke and W. F. van Gunsteren, ChemPhysChem, 2006, 7, 671 .

60 D. Gonzalez-Salgado and I. Nezbeda, Fluid Phase Equilib., 2006, 240, 161.

61 K. Liltorp, P. Westh and Y. Koga, Can. J. Chem., 2005, 83, 420.

62 E. J. W. Wensink, A. C. Hoffmann, P. J. van Maaren and D. van der Spoel, J. Chem. Phys., 2003, 119, 7308.

63 C. A. Koh, H. Tanaka, J. M. Walsh, K. E. Gubbins and J. A. Zollweg, Fluid Phase Equilib., 1993, 83, 51.

64 H. Tanaka and K. E. Gubbins, J. Chem. Phys., 1992, 97, 2626. 65 S. W. Cochran, J. C. Holste, K. N. Marsh, B. E. Gammon and K. R. Hall, Fluid Phase Equilib., 1993, 88, 171.

66 S. Z. Mikhail and W. R. Kimel, J. Chem. Eng. Data, 1961, 6, 533.

67 J. M. Simonson, D. J. Bradley and R. H. Busey, J. Chem. Thermodyn., 1987, 19, 479.

68 C. Synowietz, in 1.1 Introduction, Springer Materials - The Landolt-Börnstein Database, ed. K. Schäfer, http://www. springermaterials.com, DOI: 10.1007/10201852_1.

69 A. D. Becke, J. Chem. Phys., 1993, 98, 5648.

70 C. T. Lee, W. T. Yang and R. G. Parr, Phys. Rev. B: Condens. Matter Mater. Phys., 1988, 37, 785.

71 P. J. Stephens, F. J. Devlin, C. F. Chabalowski and M. J. Frisch, J. Phys. Chem., 1994, 98, 11623.

72 S. H. Vosko, L. Wilk and M. Nusair, Can. J. Phys., 1980, 58, 1200.

73 S. Grimme, J. Antony, S. Ehrlich and H. Krieg, J. Chem. Phys., 2010, 132, 154104.

74 F. Neese, The ORCA program system, WIREs Comput. Mol. Sci., 2012, 2, 73.

75 A. Schäfer, H. Horn and R. Ahlrichs, J. Chem. Phys., 1992, 97, 2571.

76 F. Weigend and R. Ahlrichs, Phys. Chem. Chem. Phys., 2005, 7, 3297.

77 S. F. Boys and F. Bernardi, Mol. Phys., 2002, 100, 65.

78 Y. Zhao and D. G. Truhlar, J. Chem. Theory Comput., 2008, 4, 1849.

79 Y. Zhao and D. G. Truhlar, Acc. Chem. Res., 2008, 41, 157. 80 Y. Zhao and D. G. Truhlar, Theor. Chem. Acc., 2008, 120, 215. 81 M. J. Frisch, G. W. Trucks, H. B. Schlegel, G. E. Scuseria, M. A. Robb, J. R. Cheeseman, G. Scalmani, V. Barone, B. Mennucci, G. A. Petersson, H. Nakatsuji, M. Caricato, X. Li, H. P. Hratchian, A. F. Izmaylov, J. Bloino, G. Zheng, 
J. L. Sonnenberg, M. Hada, M. Ehara, K. Toyota, R. Fukuda, J. Hasegawa, M. Ishida, T. Nakajima, Y. Honda, O. Kitao, H. Nakai, T. Vreven, J. A. Montgomery Jr, J. E. Peralta, F. Ogliaro, M. Bearpark, J. J. Heyd, E. Brothers, K. N. Kudin, V. N. Staroverov, R. Kobayashi, J. Normand, K. Raghavachari, A. Rendell, J. C. Burant, S. S. Iyengar, J. Tomasi, M. Cossi, N. Rega, J. M. Millam, M. Klene, J. E. Knox, J. B. Cross, V. Bakken, C. Adamo, J. Jaramillo, R. Gomperts, R. E. Stratmann, O. Yazyev, A. J. Austin, R. Cammi, C. Pomelli, J. W. Ochterski, R. L. Martin, K. Morokuma, V. G. Zakrzewski, G. A. Voth, P. Salvador, J. J. Dannenberg, S. Dapprich, A. D. Daniels, Ö. Farkas, J. B. Foresman, J. V. Ortiz, J. Cioslowski and D. J. Fox, Gaussian 09, Revision C.01, Gaussian, Inc., Wallingford, CT, 2010.

82 T. H. Dunning, J. Chem. Phys., 1989, 90, 1007.

83 R. Ludwig, Angew. Chem., Int. Ed., 2001, 40, 1808-1827.

84 G. Z. Han, Y. L. Ding, P. Qian, C. Zhang and W. Song, Int. J. Quantum Chem., 2013, 113, 1511.
85 C. Corsaro, J. Spooren, C. Branca, N. Leone, M. Broccio, C. Kim, S. H. Chen, H. E. Stanley and F. Mallamace, J. Phys. Chem. B, 2008, 112, 10449.

86 S. Kashtanov, A. Augustson, J. E. Rubensson, J. Nordgren, H. Agren, J. H. Guo and Y. Luo, Phys. Rev. B: Condens. Matter Mater. Phys., 2005, 71, 104205.

87 K. R. Wilson, M. Cavalleri, B. S. Rude, R. D. Schaller, T. Catalano, A. Nilsson, R. J. Saykally and L. G. M. Pettersson, J. Phys. Chem. B, 2005, 109, 10194.

88 R. F. Lama and B. C. Y. Lu, J. Chem. Eng. Data, 1965, 10, 216. 89 L. Abello, J. Chim. Phys. Phys.-Chim. Biol., 1973, 70, 1355.

90 I. Tomaszkiewicz, S. L. Randzio and P. Gierycz, Thermochim. Acta, 1986, 103, 281.

91 J. A. V. Butler, D. W. Thomson and W. H. Maclennan, J. Chem. Soc., 1933, 136, 674.

92 M. W. Chase, NIST-JANAF Thermochemical Tables, J. Phys. Chem. Ref. Data, Monograph No. 9, 4th edn, 1998.

93 T. S. Khasanshin, T. B. Zykova and S. P. Bunko, High Temp., 1997, 35, 149. 